\title{
ORAL PREDNISOLONE PHOSPHATE THERAPY
}

\author{
BY \\ E. BAILEY. D. MURPHY and H. F. WEST \\ From the Rheumatism Research Unit, Nether Edge Hospital. Sheffield
}

(RECEIVED FOR PLbliCATION JUNE 19, 1962)

In a previous communication (Bailey, Murphy and West, 1961) we reported the urinary excretion of prednisolone and prednisone of a number of children who were not responding to prednisolone therapy. From the findings we concluded that some ill children absorb only a fraction of the dose of prednisolone given to them and we suggested that until a surer way of giving prednisolone was found it might be wise to give the more watersoluble steroid triamcinolone which they absorbed well. Recently, highly water-soluble prednisolone phosphate tablets have become available, so we have repeated some of the studies. Urine specimens have been provided as previously by Professor R. S. Illingworth and Dr. John Lorber of the University Department of Child Health. The results are reported because they suggest that the phosphate tablets will prove of considerable clinical value.

\section{Methods}

The tablets of prednisolone $(5 \mathrm{mg}$.) were given whole in some cases and crushed in others. The phosphate tablets, containing $5 \mathrm{mg}$. of prednisolone, were given dissolved in water. Aliquots of the urine collections were extracted with ethyl acetate; the extracts were purified and the prednisolone and prednisone isolated by paper chromatography. They were then reacted with isonicotinic acid hydrazide and measured by ultraviolet absorption in a Unicam spectrophotometer at 405 mil. Each urine was extracted twice and two aliquots of each were measured. This method of measuring the free hormones in urine is both exacting and time consuming. When comparatively large amounts are to be measured, as in this study, time can be saved by employing gas chromatography after partial purification of the extracts (Bailey, 1963).

\section{Results}

Children. The Table gives details of the children treated, the doses given, the amounts of prednisolone and prednisone excreted, the creatinine excretion and, in some cases, the excretion of total 17-hydroxycorticosteroids (17(OH)CS) (Appleby, Gibson, Norymberski and Stubbs, 1955). It will be seen that in each case mcre prednisolone and prednisone was excreted when the phosphate tablets were given. The interpretation of the figures will be considered below.

Adults. A rheumatoid arthritic patient who had had a partial gas:rectomy was responding very poorly to $10 \mathrm{mg}$. prednisolone given in the form of enteric-coated tablets. When he was given the same dose of prednisolone phosphate he improved considerably. It was found that his excretion of prednisolone rose $50^{\circ}$, when he was given plain crushed tablets and $100 \%$ when given the soluble phosphate tablets. Another patient responding normally to $10 \mathrm{mg}$. prednisolone was given the phosphate tablets. Her excretion of prednisolone rose by $25 \%$. Thereafter five rheumatoid patients were changed from plain to phosphate tablets and in four of the five the clinical effectiveness was clearly enhanced. These patients were aware of the effect of the phosphate tablets about two hours after taking them and were aware of their effect diminishing after 10 hours. Despite the latter they preferred the phosphate. While receiving plain tablets twice daily they were not aware of the effect starting and stopping and some found that more analgesic tablets were necessary. These findings suggest that the phosphate tablets were more rapidly absorbed than the plain. So far we have not found the phosphate tablets a canse of dyspepsia.

Prednisolone Excretion of Controls. Before considering the interpretation of the findings it is necessary to know something of the excretion of prednisolone by normal subjects. The Figure shows the excretion in the eight hours after the administration of a single dose, at 9 to 10 a.m. The subjects were three members of staff. The scatter of the results was subsequently found to be partly due to differences in the rate of urine flow. At rates of urine flow of 1 to $2 \mathrm{ml}$. a minute there was onethird less excreted compared with rates of $6 \mathrm{ml}$. or more. As prednisolone is bound by transcortin 
TABLE

URINARY EXCRETION OF PREDNISOLONE AND PREDNISONE BY ILL AND CONVALESCENT CHILDREN RECEIVING PREDNISOLONE (P) AND PREDNISOLONE PHOSPHATE (PP) TABLETS



Figures in parentheses are 'adjusted' for differences in creatinine excretion.

* Crushed tablets. $\quad+=12$-hour urine collection.

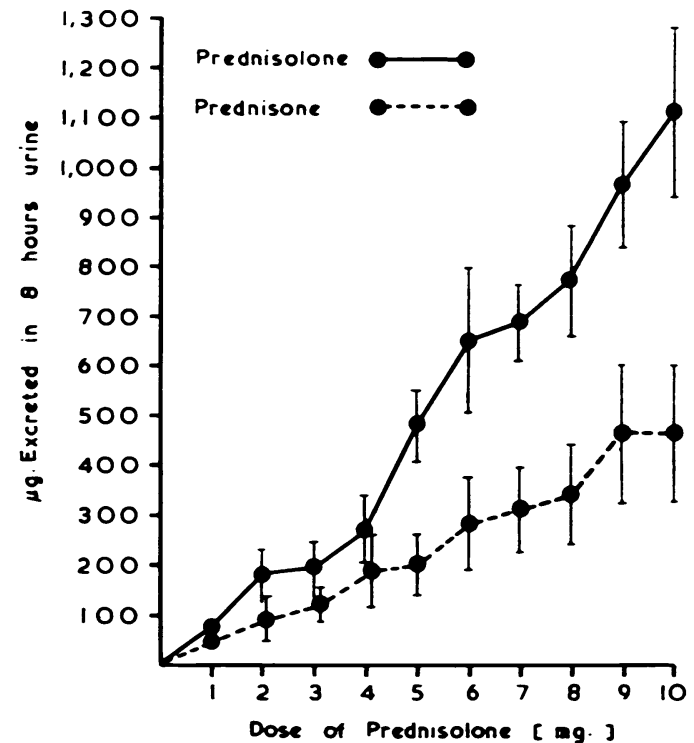

FigURE.-The urinary excretion of prednisolone and prednisone in the eight hours following single doses of prednisolone. Each point represents the mean of assays made in duplicate or triplicate from three normal subjects. The vertical lines show the standard deviations.
(Daughaday, 1958) one might have expected the curve to be flatter in the lower dose range, but in untreated individuals the hydrocortisone concentration will be highest in the morning and not until it has fallen will all the transcortin binding sites be available to bind prednisolone. Had the subjects' secretion of hydrocortisone been suppressed by previous therapy more prednisolone would have been protein-bound and less free to be filtered in the kidney and this would have been particularly noticeable at low dose levels. This may explain in part why the subjects in the Figure excreted approximately $10 \%$ of the dose given, whereas the patients in the Table, who were on continuous therapy, excreted less. From the Figure it is seen that when therapeutic doses are given the excretion of prednisolone is proportional to the dose.

Interpretation. The greatly increased excretion of prednisolone and prednisone seen when prednisolone phosphate was given could be due to increased absorption and, or, to a more rapid rate of absorption producing a high blood level that quickly saturated the specific binding protein and allowed more prednisolone to be free to diffuse into 
tissues and be filtered in the urine. In a normal subject a change in the total excretion of $17(\mathrm{OH}) \mathrm{CS}$ should provide some evidence of what is happening. If, for instance, the excretion of prednisolone plus prednisone rose by $4 \mathrm{mg}$., solely because it was more rapidly absorbed, the total $17(\mathrm{OH}) \mathrm{CS}$ excretion would rise less than $4 \mathrm{mg}$. (3-4 $\mathrm{mg}$. derived from the free hormones minus 1-2 mg. 17( $\mathrm{OH}) \mathrm{CS}$ metabolites that would not have been formed). If, on the other hand, the rise of $4 \mathrm{mg}$. prednisolone and prednisone was due solely to increased intestinal absorption the excretion of total $17(\mathrm{OH}) \mathrm{CS}$ would rise 12-16 mg., since normally two to three times as much metabolite would be excreted.

In ill children both liver function and glomerular filtration may be defective. The former will result in a rise in prednisolone excretion and a fall in the amount of the $17(\mathrm{OH}) \mathrm{CS}$ excretion that can be ascribed to liver metabolites. The latter will result in less prednisolone being excreted and more being excreted as $17(\mathrm{OH}) \mathrm{CS}$ metabolites.

Turning to the Table, the following interpretations are suggested: Patient S.G. excreted so little $17(\mathrm{OH}) \mathrm{CS}$ and free hormone that a gross defect in absorption must have been present. Patient C.G. had systemic lupus erythematosis, with renal damage, and a diastolic blood pressure of $150 \mathrm{~mm}$. $\mathrm{Hg}$. If her excretion figures are related to her creatinine excretion, which is permissible in her case, as she had her doses six hourly, it will be seen that with the phosphate tablets she excreted an extra $1.4 \mathrm{mg}$. free hormones and $8 \mathrm{mg}$. total $17(\mathrm{OH}) \mathrm{CS}$. The major rise in $17(\mathrm{OH}) \mathrm{CS}$ excretion in her case can only be explained by increased absorption. Patient D.P. was very ill with leukaemia. The rise in her excretion of free hormone was similar to the rise in $17(\mathrm{OH}) \mathrm{CS}$ excretion (the prednisolone was given 12 hourly, so corrections for incomplete 24-hour collections based on creatinine excretion are not very reliable, i.e. the loss may have occurred when the excretion rate was high or low). Her figures may be interpreted as showing an increased excretion of prednisolone when the phosphate tablets were given, due to rapid absorption with a possible further increase due to liver dysfunction. The same reasoning applies to $\mathbf{N}$.J. who was also very ill and whose liver was hardly able to produce any 17(OH)CS metabolites. Patient M.H. who had chorea and active carditis showed the smallest rise on phosphate tablets. The rest of the children were ambulant. In the case of M.W. incomplete absorption of the plain tablets was likely, but for the others it is not possible to deduce how much of the rise was due to rapid absorption and how much to increased absorption.

\section{Discussion}

In the case of adults one can predict fairly accurately the minimum effective oral dose of a corticosteroid that will markedly affect rheumatoid arthritis, asthma or Addison's disease. Children, on the other hand, often have to be given very much more than one would expect they would need, for rheumatic diseases, nephrosis and the adrenogenital syndrome. From the data in this paper and those published previously (Bailey et al., 1961) we deduce that the higher doses needed have been due, at least in part, to the slow absorption of prednisolone and, by inference, of other non-polar corticosteroids (e.g. cortisone acetate, prednisone, methyl prednisone and dexamethasone). When such corticosteroids are absorbed slowly or the intestinal contents are hurried along, they may reach the regions of bacterial action and be destroyed. We have found that the effectiveness of prednisolone and its rate of absorption, when given in the form of enteric-coated tablets or capsules, falls off rapidly as the solution time of the coating increases. The disintegration time of plain tablets could be too long, and in this case crushing them might aid absorption, but this factor is not likely to be operative since reputable pharmaceutical firms have been aware of this danger for a very long time. It has been found by at least one pharmaceutical firm that prednisolone has to be finely ground to be fully effective orally in adults.

We have measured the free prednisolone and prednisone in the urine rather than the free $\Delta 1-4,3-$ ketosteroids because the former provide the best available guide to the effective concentration of these hormones in the body (see Greaves and West, 1960; West, 1960). In this study the increased excretion of prednisolone, when the phosphate was given, was associated with increased clinical effectiveness in the adults, but in the case of the children the phosphate was only given when specimens were needed for the study and no clinical comparisons were made. That the rate of excretion of hydrocortisone and prednisolone is a valuable guide to their effective concentrations in tissues is confirmed by comparing the concentration in saliva with that excreted in the urine while the saliva is being collected (unpublished observations). The comparison does not apply to highly polar steroids. When triamcinolone is given the salivary concentration is approximately one-tenth that expected from that rate of excretion in the urine. This is iue to the barrier to polar non-ionized substances presented by the salivary cell membrane. Comparisons of the rate of urinary excretion and the salivary concentration of betamethasone, dexa- 
methasone and paramethasone are made difficult by the very low concentrations found.

The alternative means of assessing the effective concentration of a corticosteroid is to measure the non-protein bound concentration in the blood. This is a very difficult procedure which is not likely to become a practical proposition for hospital laboratories.

\section{Summary and Conclusion}

From a study of the urinary excretion of prednisolone and prednisone by children it is concluded that some children absorb prednisolone poorly, but that when prednisolone phosphate tablets are given the absorption is excellent and rapid. From the amount of prednisolone excreted following the phosphate tablets and from their clinical effectiveness it is concluded that they provide a higher effective blood concentration than an equal dose of plain prednisolone tablets.
It is recommended that in order to give a known dose of prednisolone to children and to those adults who may not absorb prednisolone well because of alimentary dysfunction, prednisolone phosphate tablets should be used.

Thanks are due to Mr. J. C. H. Hanson of Glaxo Laboratories for providing generous supplies of prednisolone phosphate tablets. This work was made possible by research grants from the Sheffield Regional Hospital Board and the Medical Research Council.

\section{REFERENCES}

Appleby, J. I., Gibson, G., Norymberski, J. K. and Stubbs, R. D. (1955). Indirect analysis of corticosteroids. 1 . The determination of 17-hydroxycorticosteroids. Biochem. J., 60, 453 .

Baiky, E. (1963). The gas-chromatography of corticosteroids. J. Endocr. In the press.

, Murphy, D. and West, H. F. (1961). Corticosteroid therapy in childhood. Lancet, 2, 347

Daughaday, W. H. (1958). Binding of corticosteroids by plasma proteins. III. The binding of corticosteroid and related hormones by human plasma and plasma protein fractions as measured by equilibrium dialysis. J. clin. Invest., 37, 511.

Greaves, M. S. and West, H. F. (1960). Relation of free corticosteroids in urine to steroid dosage. Lancet, $1,368$.

West, H. F. (1960). The use of urinary steroid assays to determine the effect of corticotropin in clinical practice. Pruc. Sheffield Corticotropin Conf. Munksgaard, Copenhagen, p. 33 